pressing the very essence of the things to which they re. late; hence, too, their use in forming a broad platform, on which the results of all the lower processes of mind are plainly recorded, and from which we can commence those higher forms of mental activity, which give to reason its all but infinite range, and all but omnipotent force." (Morell's Psychology, p. 184.)

Words are, in fact, the final expression of that mental process, as well as the depository of its final results, consummated through the instrumentality of the faculty of language, by which knowledge becomes definite, ex. act, and communicable; and they enable us, through our reasoning and reflecting faculties, not only to judge explicitly, but also to frame a method by which our judgments may be articulately expressed.

For the constructive faculty of language, from its power of combining words together, enables us, as I have said, to express the mutual relations of objects, the relations of our thoughts to objects, and the order and relations of our thoughts to themselves; and thus, on the one hand, continuous speech becomes moulded step by step into a complete organ of thought; and on the other, a sentence or proposition in language becomes equivalent to a complete thought in psychology, meaning of course by this formal thought, in its logical acceptation, that is : "a distinct act of comparison between two terms, in which we apprehend the relationship that exists between them." In the development of the intellectual consciousness, the reasoning and reflecting faculties are the latest to be evolved, and the last to reach their maturity; they are the most distinguishing attributes of humanity, of " the being that looks before and after"; for, while the moral and religious intuitions are the sole prerogatives of man, and constitute an im. mutable distinction between him and the whole animal creation, it is through his reasoning and reflecting faculties that he sees clearly the bases upon which moral obligation rests, and that religion becomes to him "a reasonable service," and that his is an intelligent, vo. luntary, and cheerful dependence upon an all-perfect Being, infinite in wisdom, power, and goodness.

When the exalted, pure, and holy moral and religious intuitions and feelings are directed, guided, and strength. ened by the dominating influence of the reasoning and reflecting faculties, then it is, that the true greatness of the human character is manifested and felt by others.

From observation and experiment, from the joint operation of the perceptive faculties and the reasoning and reflecting powers, result the creation of science, and the achievements of science. Mr. Morell has well ob. served, "The proper function of reason is to create knowledge or science. The understanding alone can never do this; it can aualyse, distinguish, form concepts, construct propositions, weave them into arguments, perform, in a word, any formal process within the data furnished to it, but it can never go beyond the barriers of its own definitions. When, however, we grasp a truth by the power of reason, on the other hand, it implies far more than the attainment of a bare definition of it. It implies that we have penetrated to the centre; that we can trace its pedigree in the world both of matter and form; that we can regard it as one link in a connected chain, of which we are able to tell the antecedents, and to foretell the consequents; that we can recognise it, in fine, as a particular manifestation of some great and universal law, the operations of which we have learned to comprehend and apply." (Morell's Psychology.)

But, in the progress of science, we must not overlook the importance of the imaginative or inventive faculty; and I shall close this imperfect and brief survey of the leading phenomena of the mental states, by reiterating what I have elsewhere said on the relations of the im. aginative and reasoning powers. "Out of the funciful combinations and groupings of external nature, new conceptions are formed; and by the imaginative faculty, 302 we are placed in scenes, circumstances, and relations, in $\subseteq$ which our actual experience has never placed us, and $\Rightarrow$ from which, in consequence, as new sources of thought, $\stackrel{\vec{S}}{+}$ new conceptions arise. But, while these new creations 0 may bear strongly the impress of the æsthetic and emotional character and tendencies of our minds, the highest. efforts of the creative faculty involve equally the agency of the intellectual powers, of collocation, analysis, and comparison, to achieve their loftiest triumphs. And thus, while, on the one hand, ideality is dependent upon the intellectual powers for the development of its highest and sublimest flights; so, on the other, is the understanding indebted to the imaginative faculty for those ideal combinations and conceptions, which, independentry of their artistic value and importance, are seen to be so operative in the common affairs of human life, suggesting those pictures of the future which are ever before our eyes, and are our animating springs of action, with those visions of enjoyment, never perhaps to be realised, and their prospects of anticipated evil, that often prove to be an exaggeration of the reality, prompting the investigations of science, that are gradually unfolding the sublime plan on which the universe is governed, and leading to a continual aspiration after those higher forms of moral and intellectual beauty, which are inseparably connected with purity and love."

"Every system of philosophy," to conclude in the words of Morell, "rests in God, as its highest idea and its final aim. To see the Divinity as the beginning, the middle, and the end of all things, is the cuiminating point of all human thought. 'Thus it is the goal, not only of providence, not only of redemption, but also of the no less divine laws of reason itself, that God should be all in all."

\section{BENEFICIAL EFFECTS OF BELLADONNA AS A SEDATIVE IN EPILEPSY.}

By William Sankey, Esq., F.R.C.S., Dover.

Catharine P. M'Kenzie, aged 5 years, came under treatment September 26th, 1860, suffering from epilepsy. The account given by her mother was, that from her birth she had been a remarkably healthy child till two years ago, when she was attacked with diarrhœa, which was allowed to go on for four or five weeks, producing great weakness. Soon after this, the first fit occurred; and for nearly three months she had two or three daily. These soon ceased, without medical assistance; and she got well, and continued so till the summer of 1860, when she was suddenly again seized with the fits, accompanied with loss of power on the right side. The fits continued increasing in spite of various modes of treatment, and becarne almost inces. sant day and night, with total loss of power in the limbs and muscles of the neck; but she still retained a degree of consciousness. The treatment consisted in purgatives and counterirritation by blisters behind the ears and nape of the neck, succeeded by various tonics and cod.liver oil; the bowels being kept regular by small doses of castor oil. The state of the poor little sufferer at this time appeared hopeless.

On December 27th, I prescribed one-twelfth of a grain of the extract of belladonna to be given three times a day, gradually increasing the frequency of the doses to every six and four hours. The effect was most decided; the fits, instead of recurring every hour or two, on the lst of January only occurred once in twenty.four hours. The appetite was improved, and the digestion was good. As the beneficial effect of the remedy was now established, and the pupils were rather dilated, it was deemed proper gradually to lessen the frequency of the doses, which was done till only one dose was given in twenty-four hours. During this time,

. 
recovery went on steadily and progressively. On the 8th of March I last saw the patient, and was told by her mother that she had had no fits for the last two days, and for the four previous days only one each night, and that less in violence or duration. She is still unable to stand or walk, but has perfect use of her hands, and speaks tolerably well. I consider that time is now only required, with the assistance of exercise in the open air, ete., to complete the cure.

\section{A S E O F A P O P L E X Y.}

\section{By D. R. McNAB, Esq., Epping.}

A RoBUst labouring man had suffered about three years with frequent headaches, and had on one occasion "pitched suddenly forward" while at his work. One day, between 12 and 1 p.Mr., he was seized with violent pain in the head; and he left his fellow-labourer to go to a ditch, in which to bathe his head with the water. At dinner-time he lay down for a short time; but in the afternoon he tied some hay. At about 5 p.M., he gave rup work, and attempted to walk home; he was, however, unable to proceed, and was taken in a cart. Just before he reached the surgery, he called out "Stop at the Surgery"; but, when I saw him there in the cart, he was quite insensible. He was taken on to his own house in the town, and continued insensible till he died, at eight o'clock the next morning. No hopes were entertained of his recovery from the appearances. The face was pale; the breathing like that of quiet sleep, but thoracic rather than abdominal; the pulse somewhat slower perhaps than natural, and soon becoming irre. gular. The whole body was inert as in sleep; but there seemed a consciousness of pain upon the application of mustard and at the prick of a lancet. The pupils were closely contracted; but the eye, when examined, kept continually rolling in a singular manner from side to side in the orbit.

At the post mortem examination, the dura mater was congested. The brain appeared as if bursting through the dura mater; both lateral ventricles were filled and aistended with dark coagula. In the left ventricle, upon the thalamus opticus and the corpus striatum and on the opposite wall of the ventricle, there was a diseased pulpy mass of brain-like substance mixed with blood, which appeared to have burst through the lining mem. brane, and given rise to the hæmorrhage.

An American Professor. Professor Day (not he of St. Andrews) is just six and a.half feet high in his stockings. His weight is $3101 \mathrm{~b}$., and he measures seven feet in girth. He is the tallest and biggest man in the regiment, and is noted for his great strength as well as his huge proportions. He has been known to shoulder a 600 . bale of cotton, and has frequently taken a whisky barrel by the chines, raised it at arms' length, and drunk at the bunghole. On one occasion he threw a mustang pony and his rider over a ten-raii fence. For this offence he was tried and convicted in the Circuit Court of Lauderdale county, and fined 500 dollars. This remarkable man is the youngest and smallest of seventeen brothers. His father is two and a-balf inches taller than he is, but not so thick set. His brothers are taller, but none of them are so stout as the Professor. It is necessary to remark that his father has been twice married, and has eight children by his first wife and nine by his present wife. The Professor is the principal of the Marion High School, and is a learned man in every sense of the word. He is a master of six languages, and as a mathematician he has no superior. $\mathrm{He}$ is, besides, one of the best men living, and is noted for his good nature. He never had but one fight in his life, and then bo killed a horse and nearly murdered a man.

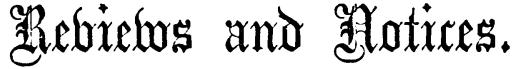

Autobiography of the Rev. Dr. Alexander CarLyle, Minister of Inveresk; containing Memorials of the Men and Events of his Time. Pp. 576. Edinb. and London. 1860.

THIs work contains curious information concerning many medical men who flourished in Edinburgh and London about the middle of the last century. Dr. CARLYLE was born in 1722 , and died in 1805 . He commenced writing the present work at the age of 79 ; giving as his reason, a resolution he had long formed to note down certain facts within his knowledge, that might be subservient to a future historian, if not to embellish his page, yet to keep him within the bounds of truth and certainty. He was enabled to do this with great accuracy, in consequence of the habit he had acquired of making short notes in a diary for many years. He has written with great vigour, eloquence, and point ; and, as is well observed by the editor (Mr. Burton), the contemporary-like freshness with which he realises scenes over which long years, crowded with other recollections, had passed, looks like a phenomenon unexampled in literature. The publication of the work has been purposely delayed until the generation liable to be distressed by the outspoken experience and opinions of others, which it contains, had passed away.

It is in no way our intention to follow the life and adventures of Dr. Carlyle, as recorded in this volume. Though but the minister of a country parish in the immediate neighbourhood of Edinburgh, he mingled intimately with most of the remarkable men of his time, and was an eye-witness of several important events, such as the Porteous riot in Edinburgh and the battle of Prestonpans. $\mathrm{He}$ entered the University of Edinburgh as a student in theology in 1736, when the medical school was first rising into fame, the first Monro being Professor of Anatomy, and Dr. Sinclair Professor of the Theory of Medicine. The latter, he tells us, was the most eminent Latin scholar at that time, except the great grammarian Ruddiman. It would appear that living in Edinburgh was then wonderfully cheap, as there were ordinaries for young gentlemen, at fourpence a head, for a very good dinner of broth and beef and a roast and potatoes every day, with fish three or or four times a week, and all the small beer that was called for till the cloth was removed. In 1743, when he was a student in Glasgow, we are told that Dr. Johnstone was Professor of Medicine, and Dr. Robert Hamilton Professor of Anatomy. The former was very old, and died that year; and was succeeded by Dr. William Cullen, who had been settled at Hamilton. In those days there were but few students of physic in Glasgow University. Dr. Cullen and his successor, Dr. Black, with the younger Hamiltons, brought the school of medicine more into repute there.

In 1745, he went to Leyden, then the great resort of British students, where he lodged in the same house with Dr. John Gregory, from Aberdeen, afterwards the distinguished Professor of Medicine in Edinburgh, with whom he became very intimate.

"Gregory," he says, "when afterwards tried by the 303 